\title{
Un ensayo de microhistoria literaria: mutaciones poéticas en Lancelot o el Caballero de la Carreta y sus vínculos con las culturas francesas del siglo XII
}

CONICET, Facultad de Filosofía y Letras, Universidad de Buenos Aires, Argentina

Fecha de recepción: 16/8/2019. Fecha de aceptación: 25/8/2019.

\section{Resumen}

La historia de los amores de Lancelot y Ginebra posee una centralidad indiscutible en la producción romancesca de materia artúrica, desde que, en el siglo XII, Chrétien de Troyes sellara el destino del caballero al servicio de su reina en Lancelot o El caballero de la Carreta. De esta forma, Chrétien inventó una leyenda que rápidamente vino a competir, en términos análogos y a partir de una temática similar, con el popular mito de Tristán e Iseo, el cual, desde los oscuros parajes de la Bretaña insular, había conquistado la imaginación de los hombres medievales.

En función de esta aseveración, el objetivo del artículo es revisar la relación que el escritor establece entre las dos parejas mediante el análisis particular de El caballero de la Carreta. Presentaré algunas hipótesis relativas al tipo de amor que el caballero siente para con su reina, el cual no parece reproducir los sentimientos de Tristán por Iseo. Finalmente, intentaré esbozar un panorama de la posición que el texto ocupa en toda la obra de Chrétien de Troyes, especular sobre las líneas directrices que guiaron su producción en general y proponer algunas explicaciones de cómo el roman responde a coordenadas intelectuales específicas de su momento de escritura. 
An essay of literary microhistory: poetic mutations in Lancelot, the Knight of the Cart and its links with the French cultures of the $12^{\text {th }}$ century

\begin{abstract}
The history of Lancelot and Guinevere's loves has an indisputable centrality in the romance production of Arthurian material, since, in the $12^{\text {th }}$ century, Chrétien de Troyes sealed the fate of the knight in the service of his queen in Lancelot, The Knight of the Cart. In this way, Chrétien invented a legend that quickly came to compete, in analogous terms and from a similar theme, with the popular myth of Tristan and Iseut, which, from the dark places of insular Britain, had conquered the imagination of the medieval men.
\end{abstract}

Based on this assertion, the objective of the article is to review the relationship that the writer establishes between the two couples through the particular analysis of The Knight of the Cart. I will present some hypotheses concerning the type of love that the gentleman feels for his queen, which does not seem to reproduce Tristan's feelings for Iseut. Finally, I will try to sketch an overview of the position that the text occupies in the whole work of Chrétien de Troyes, speculate on the guidelines that guided its production in general and propose some explanations of how the roman respond to specific intellectual coordinates of his time of writing.

Keywords: Tristan and Iseut legend; arthurian roman; Chrétien de Troyes.

\title{
1. La obsesión Tristán: en el umbral de la narrativa artúrica
}

De los escasos fragmentos franceses que nos llegaron de la leyenda tristaniana, el lai de María de Francia, Madreselva (Chievrefueil), ofrece un testimonio relevante de su difusión. En efecto, en los primeros versos del lai se afirma:

\footnotetext{
Plusur le m'unt cunté e dit

Ejeo l'ai trové en escrit

De Tristram e de la reïne,

De lur amur ki tant fu fine

dunt il eurent meinte dolur

puis en mururent un jur. ${ }^{2}$

(vv. 5-10) [resaltado propio]
}

2 "Muchos me han contado y hablado, yyo lo he encontrado por escrito, de Tristán y la reina, de su amor que fue tan puro, por el que recibieron abundantes dolores y después murieron en un solo día" (María de Francia, 1994: 141). Aunque pueda tratarse de una captatio benevolentiae, es interesante resaltar que María apela a la idea de popularidad para justificar la elección de la leyenda como tema de su lai. 
El indefinido plusur pone de manifiesto la notoriedad de la historia al referir una multiplicidad de voces que, previo a María de Francia, habrían actualizado las vicisitudes de esta pasión febril, y que, más tarde, Béroul y Tomás de Inglaterra, dos de los modernos autores del siglo XII, fijaron de manera perenne en la memoria de la escritura.

Me interesa leer en el registro de esa pluralidad la huella de una celebridad y el recuerdo de su divulgación en los ambientes en los que primeramente se irradiaron las literaturas francófonas. Los versos liminares de Madreselva permiten especular sobre la repercusión e injerencia de esta fábula en el imaginario cortesano de la época, y atribuirle, en los albores de las narrativas caballerescas y en condiciones de circulación y recepción análogas, una popularidad semejante a la que brindamos en la actualidad al rey Arturo y a los caballeros de la Mesa Redonda. ${ }^{3}$

Ahora bien, de acuerdo con los registros literarios conservados, la supremacía de la leyenda no permaneció inalterable a través del tiempo. Su fama logró mantenerse gracias al impulso que algunos autores le proporcionaron; entre ellos, Chrétien de Troyes. Sin embargo, las opiniones del escritor champañés respecto de los amantes de Cornualles no fueron, en líneas generales, halagüeñas. Sus romans contienen alusiones críticas que revelan, de manera paradójica, la enigmática fascinación que ejerció sobre él este bello cuento de amor y de muerte. ${ }^{4}$ La atracción resultó predominante en su segundo roman, Cligès, no solo debido a que en él el protagonista ofrece una imagen distorsionada del héroe insular y a que el amor de Cligès y Fenice se presenta como una adaptación edulcorada de la pasión que consume a Tristán e Iseo, sino porque en el prólogo Chrétien asegura haber compuesto una versión protagonizada solo por el rey Marc e Iseo la rubia. Esta curiosa transformación conduce a inferir que la manera en que el escritor focalizaba la historia se desviaba de las communis opinio y que su interés por reproducirla decayó prontamente a favor de una exploración literaria más personal del tema (Delage, 1979).

3 El amplio conocimiento de la historia por el público medieval del siglo XII ya fue señalado por Michel Zink cuando afirmaba: "L'histoire des amants de Cornouailles, qui, dans l'état où elle nous est parvenue, mêle au fonds celtique des emprunts à l'antiquité classique, a été connue très tôt par les littératures romanes. Les troubadours y font allusion, semble-t-il, dès les années 1150-1160. Le poème de Béroul (ca. 1170-1175) et celui de Thomas (peu après 1172) sont contemporains des premières œuvres de Chrétien et légèrement antérieurs à Cligès (1176-1177) [...]. Le témoignage concordant de Thomas et de Giraud de Barri touchant un certain Breri, qui aurait raconté l'histoire dans la première moitié du XIle siècle, mérite considération. Béroul (1265-68) comme Thomas (2107 et ss.) insistent sur la diversité des versions du 'conte' et sur la supériorité de la leur. Il est clair que cette légende, bretonne mais non arthurienne, ou du moins reliée à ses débuts de façon aussi artificielle que ténue au monde arthurien par l'épisode du serment ambigu, a connu dès la seconde moitié du XIle siècle un succès considérable" (1987: 23).

4 En su antología sobre la literatura francesa de la Edad Media, Philippe Walter intitula "La obsesión anti-tristaniana de Chrétien de Troyes" el capítulo consagrado a su producción, y lo inicia aseverando: "Chrétien est fasciné par la légende tristanienne. Il en propose une relecture critique dans Cligès. Dans une de ses chansons d'amour il condamne le breuvage fatidique" (1993: 86). De manera similar, Matilda Tomaryn Bruckner señala: "If, in general, the story of Tristan and Iseut remains a constant subtext in Chrétien's romances, in Cligès he follows explicitly the model of the two-generational legend in his own bipartite narrative [...]" (2000: 26). Por ultimo, nuevamente Michel Zink ya había expresado esa relación ambigua, tensa, que los escritores mantenían con la leyenda: "Mais il est bien vrai que les poètes, et Chrétien plus que tout autre, quand bien même ils avouaient leur fascination, ne se sont pas identifiés à Tristan sans réticences" (1987:24). 
Otra explicación posible de su influjo es que la trágica pasión ${ }^{5}$ recogía y llevaba a su expresión última las convenciones de la fin'amor, noción cultural y literaria que, de forma simultánea, se fue irradiando desde el mediodía francés. ${ }^{6}$ Sin embargo, la similitud encerraba también diferencias que apartaban a la leyenda de la ideología trovadoresca: por un lado, el carácter igualitario del hombre y la mujer en función de la pasión que los consume (mientras que, de acuerdo con la concepción lírica, el amante está al servicio exclusivo de la altiva dama) y, por el otro, la constitución de una simbiosis alarmante que conduce a la pérdida de la individualidad y a la indiferenciación: dos que no son sino uno. ${ }^{7}$ Chrétien se esforzó por distanciar a sus personajes de esta fusión esencial, de esta comunión espiritual entre el hombre y la mujer. Sus heroicos caballeros (Erec e Yvain, por ejemplo) se batieron interna y externamente para alcanzar una síntesis armoniosa entre las armas y el amor y evitar caer en la disolución del yo. Aunque es preciso convenir que, en El Caballero de la Carreta, penúltimo roman de Chrétien, la preservación de la individualidad no constituye el objetivo principal de la conducta caballeresca. Lancelot no solo reproduce, sino que perfecciona la exaltación sentimental y guerrera de Tristán, ${ }^{8}$ aunque conserva la relación asimétrica entre Ginebra y él, propia de la fin'amor.

A partir de estas reflexiones preliminares, puede concluirse que las fábulas de Erec y Enid, Cligès y El Caballero de la Carreta demuestran que Chrétien de Troyes utilizó el prototipo tristaniano porque era un paradigma que permitía conjugar dos de las exigencias temáticas de la nueva narrativa vernácula: la hazaña guerrera y el amor; asimismo, la interpolación y rescritura de episodios nucleares de la leyenda invitaban al auditorio a recapacitar acerca de las peligrosas consecuencias de esta pasión abrasadora ${ }^{9}$ para la sociedad. Frente al embrujo del héroe bretón, el triunfo del Lancelot francés es tanto más elocuente por cuanto superó, desde el momento en que subió a la carreta de la ignominia, cualquier otra imagen de amante que las

5 Debemos tener también presente que el patetismo amoroso puede rememorar la historia de Dido, accesible al mundo de la corte Plantagenet gracias al Roman d'Eneas, el cual, junto con el Roman de Troie fueron modelos de composición literaria para los autores en lengua vernácula.

6 Es importante señalar que las comunicaciones entre la lírica trovadoresca, la narrativa cortés y el folklore bretón se beneficiaron de la situación histórica imperante, es decir, de la puesta en relación de los múltiples territorios regidos por la dinastía Plantagenet, circunstancia que propició el intercambio de noticias literarias.

7 Este sería el ideal del fins amanz, quien aspira a una fusión absoluta con el objeto de su pasión. Sin embargo, este anhelo nunca llega a concretarse. De ahí la conocida paradoja de un deseo insatisfecho que no conduce sino a la muerte: del deseo, si se consuma el amor, y de los amantes, si no se lo logra.

8 En líneas generales, la crítica no ha favorecido esta correspondencia entre los héroes y sus pasiones, sino que ha analizado, principalmente, los vínculos de Le chevalier de la charrette con la lírica trovadoresca, debatiéndose entre considerar el tratamiento del amor de Lancelot a Ginebra como el producto de la posición irónica o alegórica del autor ante la ideología de la fin'amor. Un repaso de las diferentes interpretaciones puede leerse en Fanny Bogdanow (1972), Pamela Raabe (1987) o Jacques Ribard (1972). No obstante, esta preferencia por vincular el amor de Lancelot y Ginebra con la lírica occitana no impidió que, por ejemplo, Douglas Kelly (1992: 297) o Jørgen Bruhn presentaran una perspectiva en la que se destaca el diálogo del roman con la historia de Tristán e Iseo: "When Lancelot is having an affair with Arthur's wife Guenevere (while, apparently trying to save her) -and when the adulterous couple cunningly escapes the accusations by way of a verbal oath which is neither false nor true, then their behaviour closely resembles Tristan and Isolde's first amourous meeting and their subsequent efficient verbal lines in several of the surviving medieval versions. When La Charrette is read in the light of Cligès, it becomes obvious that Chrétien wishes, once again, to achieve a paradoxical, perhaps even utopian- representation of adultery. But Lancelot and Guenevere's way of 'solving' the question of adultery is much closer to the solution in Cligès than the medieval versions of the Tristan and Isolde stories" (2010: 81).

9 Michel Zink afirma que "le véritable modèle du roman est, on le sait, l'histoire de Tristan et Iseut, comme Chrétien l'avoue plus loin par la voix de Fenice, mais le terme de "modèle" doit alors être pris dans un sens nouveau : il s'agit d'une réflexion sur un thème romanesque et moral, et non pas de la transcription d'une histoire supposée vraie" (1981: 20) [resaltado propio] 
narrativas corteses emergentes habrían tratado de instaurar. En contraposición a su oscuro origen literario, su persona y sus proezas caballerescas y sentimentales fueron uno de los puntos de atracción gravitacional para el roman artúrico en prosa del siglo XIII (y para el imaginario literario de temática medieval posterior).

La rememoración del lai de María de Francia y el breve repaso del vínculo entre los romans de Chrétien de Troyes y la historia tristaniana no pretenden recorrer un camino ya transitado por la crítica, centrado en el análisis del juego de intertextualidades que se entablan entre ellos. Lejos de ello, mi enfoque considera la pasión de Tristán e Iseo un tema paradigmático que, a través del uso de ciertas figuras retóricas, permite organizar la obra de Chrétien en una entidad conformada por dos partes que estarían revelando dos momentos en la producción del autor. Se trata de dos fases distintas caracterizadas por el empleo de un recurso retórico especifico, el cual permite vislumbrar paulatinas transformaciones en la composición del roman, las cuales, por su parte, prepararon el terreno para el advenimiento de las dos vertientes (en prosa y en verso) del roman artúrico del siglo XIII. En mi opinión estas variaciones compositivas se materializan a partir de El Caballero de la Carreta, pues en él Chrétien de Troyes realizó una suerte de metamorfosis retórica, reemplazando la ironía (figura que privilegió hasta Yvain, a fin de apropiarse críticamente de un fondo temático muy popular entre la naciente nobleza curial) por un recurso hermenéutico ligado a la alegoría, el integumentum, siguiendo las modas literarias que se difundieron desde los centros de formación intelectual del periodo. Se comprueba, una vez más, su interés en brindar a la materia que empleaba, proveniente de una literatura tradicional, una pátina erudita que le permitiera distinguir su obra. El cambio, asimismo, lo condujo a renovar su arte y a producir una conversión crucial tanto en la constitución del arquetipo caballeresco como en las posibilidades de significación de los episodios que integraban la fábula. Desde esta óptica, ya no era cuestión únicamente de aplicar una materia legendaria y un ideal social guerrero y nobiliario a un molde compositivo que denotaba la deuda a la herencia clásica; el roman que inauguraba podía emplear las escandalosas convenciones del adulterio trovadoresco y la sangrienta libido del caballero como la letra que escondía una verdad última de tonos morales y cristianos. En definitiva, Chrétien estaba fundando una clase de escritura que encontraría, en el ciclo Lancelot-Graal, el ámbito diegético ideal para su expansión y desarrollo.

\section{Del marco teórico y las metodologías: los desafíos de una investigación excéntrica}

2.1. Cincuenta años de estudios medievales: la perspectiva poética y la historia literaria

El planteo presentado en párrafos anteriores exige un excurso de índole teórico, por cuanto la línea de trabajo elegida puede parecer extemporal, en relación con las corrientes actuales de investigación, o errónea, puesto que, como Patrick Moran (2014) señala, el medievalismo siempre ha manifestado una cierta desconfianza hacia esta orientación crítica. 
Desde la década de los años sesenta, varios exponentes de la medievalística europea, aunque, mayormente, norteamericana, adoptaron algunos postulados formalistas que proclamaban, entre otros, la primacía de los análisis inmanentes y la auto-referencialidad del texto. Estas elecciones condujeron a desatender aspectos vinculados con los contextos de producción y recepción, tratando de superar antiguas limitaciones de una historiografía literaria de corte positivista. Pese al fervor que parecía haber despertado este aggiornamento en los estudios medievales en los años setenta, hacia la década de los ochenta, una nueva tendencia revirtió este pasajero entusiasmo y volvieron a surgir aproximaciones críticas que privilegiaron el análisis histórico, filológico y contextual.

En la actualidad, los estudios literarios consagrados a la Edad Media pueden ser descriptos, de manera un poco esquemática, como un área escindida, al menos, en dos grandes ramas: una que privilegia el empleo de herramientas provenientes de la crítica formal y de la hermenéutica y otra que se interesa por las fuentes, por aspectos históricos y antropológicos y por el estudio de las tradiciones textuales. Esta virtual división de aguas obligaría, en principio, a elegir entre un abordaje histórico-contextual o un análisis poético-formal de los textos. Si bien la afirmación carece de los matices indispensables o no menciona las excepciones que relativizan dicha generalidad, de todos modos, proporciona una idea elemental de cómo se configura el campo disciplinar y permite percibir las inexactitudes a las que la elección de uno u otro puede conducir. Pero, fundamentalmente, pone en evidencia la necesidad de adoptar una metodología que articule algunas de las líneas que conforman las dos vertientes y que, a su vez, confluyan en la elaboración de una historia literaria de la Edad Media. ${ }^{10}$ Asimismo, una historia literaria de estas características conduce, por un lado, a examinar tanto la conformación interna del texto como la existencia de condicionamientos contextuales que explicarían el empleo de recursos formales y estilísticos específicos y, por el otro, a descubrir cómo el ambiente cultural y literario -en especial uno emergente- se halla en constante reformulación debido a la aparición de nuevas formas discursivas. Desde esta perspectiva, resulta clara la utilidad de un análisis inmanente que permita recuperar, al interior del texto, la historicidad de la cultura que le es contemporánea.

En función de estas presuposiciones metodológicas, mi intención es conjugar el análisis del texto con una aproximación histórico-cultural mediante la cual explicar que la adopción en El Caballero de la Carreta del integumentum, variante profana de la alegoría, expresa no solo una mutación en el arte compositivo de Chrétien de Troyes (con las consecuencias que ello trae aparejado para la serie literaria) sino también la permeabilidad de los escenarios erudito y cortesano de la época. La dedicatoria a la condesa María demuestra que la redacción de $E l$

10 La idea, expresada de manera tan general, puede resultar equívoca, en especial, porque sostiene la necesidad de elaborar una historia literaria compuesta de lecturas puntuales, resultantes de microanálisis, como los que propongo en este artículo. Vincular una historia literaria con estudios particulares parece ser un método contradictorio, porque, justamente, la historiografía tiende a la generalidad y no al detalle, mientras que un estudio específico enfoca el detalle y se aparta de las generalizaciones. Sin embargo, pienso que la proposición merece ser discutida no solo porque permitiría un conocimiento menos categórico del pasado literario sino porque admitiría un saludable eclecticismo teórico que responda más a las demandas interpretativas de los textos que a las presunciones, a veces anacrónicas o distorsionadas, del crítico. 
Caballero de la Carreta tiene lugar en la corte de Champaña, ${ }^{11}$ centro cultural de intensa movilidad intelectual durante el siglo XII, tal como ha establecido, entre otros, John Benton (1981). Esta circunstancia permitiría especular que la permanencia de Chrétien de Troyes en la corte de Enrique el Liberal y María podría haber proporcionado al autor ciertos conocimientos que lo condujeron a revisar y a ensayar nuevas formas de componer narraciones. Ahora bien, para alcanzar estos objetivos es necesario referir previa y sucintamente algunas de las características acerca de las dos figuras retóricas anteriormente mencionadas.

\subsection{Ironía, alegoría, integumentum y los romans de Chrétien de Troyes}

Entre los diversos trabajos consagrados al estudio del estilo en la obra del escritor francés, la ironía posee preeminencia, particularmente, en las investigaciones de Peter Haidu acerca de la historicidad del estilo. ${ }^{12} \mathrm{Si}$ bien el especialista admitía que el empleo de esta figura no es exclusivo de Chrétien, ya que pueden encontrarse ejemplos en el cantar de gesta y en la poesía lírica de los primeros trovadores, consideraba que Chrétien había hecho un uso sistemático de ella al interior de sus narraciones, demostrando su deuda a, entre otros, Ovidio y a su Metamorfosis.

En los romans del maître champenois la ironía excede el carácter de simple ornamento estilístico y deviene un componente esencial para determinar su contenido semántico. En efecto, en los episodios donde la narración presenta actores al servicio de una ideología heroica y cortesana, la ironía permite entrever las discordancias, los escollos que obstaculizan la identificación del receptor con los valores allí expresados. Si bien el auditorio continúa sintiendo cierta simpatía hacia los personajes y sus aventuras, experimenta un desapego que lo lleva, en última instancia, a un juicio intelectual o moral (en general negativo) de ellos. Haidu observaba que, a partir de

11 Patricia Stirnemann y Dominique Poirel expresan respecto del: "[...] humanisme champenois du troisième quart du XIIe siècle, loin des écoles de Paris, de Chartres, d'Orléans. C'est un humanisme littéraire où l'éloquence, la rhétorique antique sont appréciées en elles-mêmes pour leur pouvoir de renouveler les discours, comme le souligne Nicolas [de Montiéramey] dans sa lettre à Adrien. C'est un humanisme qui s'accélère avec la réunion dans un petit espace de plusieurs cours et de leurs entourages (Henri le Libéral, Alexandre III, Thomas Becket, Guillaume aux Blanches Mains), les unes indigènes et les autres étrangères (Anglais, Italiens), les unes ecclésiastiques et les autres princières. Les gens de cour sont juristes, des notaires, des secrétaires, des laïcs, des 'érudits', comme disait Herbert de Bosham. Il y a pouvoir politique, sans parti dominant. Il y a tension (schisme, exil, interdit), sans violence physiques. Il y a pensée intellectuelle, sans institution. C'est une situation qui ressemble en plusieurs points à celle de la Renaissance italienne aux XIIle et XIVe siècles avec Lovati, Pétrarque et Boccace. Et tout comme cette atmosphère périphérique, contestataire, exilée fait émerger le poète fondateur de la littérature italienne du moyen âge, c'est-à-dire Dante, ainsi la renaissance champenoise du XIle siècle permet de faire surgir son astre de la littérature française, Chrétien de Troyes" (2006:180).

12 Haidu ya enunciaba la importancia de una aproximación historicista de la estilística. En efecto, en su artículo de 1982 afirmaba : "la notion de l'élucidation du sens historique répond également à une conscience moderne et aigüe de la difficulté épistémologique de cet effort. Sans aucune prétention à traiter cette problématique adéquatement, disons tout simplement que, pour cette conscience moderne, le sens n'est pas un trésor inclus dans un objet qu'il s'agit d'éplucher pour l'emporter et réussir dans une quête sémantique. Le sens, celui qui nous est accessible, résulte de l'imposition de codes interprétatifs et de choix opérationnels du lecteur moderne. Depuis le choix du problème fondamental jusqu'au dernier détail dans l'analyse textuelle, la présence de l'analyste moderne est partout dans son travail, même si celui-ci revêt, comme s'est souvent le cas en sémiotique, un aspect neutre, abstrait et 'scientifique'. Il n'est plus possible d'éluder cette responsabilité : tout au plus pouvons-nous en rendre l'aveu des présupposés nécessaire, et en développer les implications. Ce qui n'est plus possible, c'est de se cacher derrière une tradition positiviste, d'ailleurs contradictoire, pour affirmer la non-pertinence de paramètres sémantiques inconfortables. Si le style semble parfois l'aspect le plus idéaliste du texte littéraire, le moins facile à relier à la dimension historique, nous n'en affirmons pas seulement l'historicité, mais l'historicité comprise matériellement" (37) [resaltado propio]. 
Cligès, ${ }^{13}$ se había iniciado la serie de romans que, de formas diversas, incorporaban "estructuras de contradicción". Dichas estructuras utilizaban la ironía en el nivel verbal primeramente y en el nivel narrativo más tarde. Asimismo, como otros medievalistas han propuesto durante el último cuarto del siglo XX, el uso de la ironía revela la deuda de los escritores en lengua vernácula hacia las escuelas donde se enseñaban este tipo de estructuras textuales, siguiendo los preceptos de la grammatica y la rhetorica. En el contexto letrado, la ironía formaba parte de una hermenéutica cuyo objetivo era recuperar los valores morales o institucionales que no aparecían en la superficie literal del texto bíblico; en el ambiente laico, introdujo la posibilidad de comunicar valores culturales, sociales e ideológicos, tomando distancia de ellos. El alejamiento podía ir desde la sugerencia de una doble posibilidad de un elemento cualquiera y de los valores que ocultaba hasta la negación total de ellos. Su efecto era el de permitir una producción textual que no involucrara ni al enunciador ni al enunciatario en el sistema de valores expuesto, evitando establecer abierta y literalmente la negación. En consecuencia, la ironía permitía el funcionamiento de lo que Haidu denominó la semiosis disociativa, gracias a la cual lo dicho podía ser interpretado de manera contraria. Finalmente, el medievalista notaba que la ironía se encontraba en todos los romans de Chrétien de Troyes, aunque advertía que su sistematización ganaba terreno en Cligès $^{14}$ y que luego lo perdía en El Caballero de la Carreta y en $\mathrm{El}$ Cuento del Grial. Mi lectura de estos dos romans confirma la presunción y la complementa, argumentando que esa pérdida de supremacía se debe a la utilización, como adelanté en páginas anteriores, del integumentum, un recurso exegético que conduce a una multiplicidad de sentidos, de orden moral, yuxtapuestos al literal.

Distinguir la relevancia del integumentum o de la ironía en los relatos de Chrétien de Troyes no representa una fruición crítica (solamente), sino que explicita una circunstancia central en la evolución del roman artúrico de los siglos XII y XIII. En efecto, uno y otro sugieren la posibilidad de una lectura doble; sin embargo, el primero, a diferencia de la segunda, no implicaría que el enunciador y el enunciatario juzguen de manera negativa a las personas y sus acciones ni que se implante una "semiosis disociativa" que introduzca, por su parte, dos sentidos antagónicos en pugna. El integumentum adiciona, sedimenta, niveles sucesivos de interpretación, habilitando varias lecturas superadoras de la literal. Estas, por su parte, lejos de invalidarla, la complementan en un plano de significación superior. De esta manera, se logra la convivencia de, al menos, dos sentidos y la multiplicación del espectro de receptores a los cuales la narración se dirige y es susceptible de agradar.

13 La comprobación no deja de ser significativa para la tesis que trato de establecer en estas páginas: la historia de Cligès intenta desmoronar el mito de un amor perfecto e incomparable pergeñando uno similar pero radicalmente diferente; al mismo tiempo el narrador, gracias a una fina ironía que se cuela entre los intersticios del relato, sonríe burlón ante la nimiedad de la fuente como la de su adaptación. 
2.2.1. Alegoría e integumentum: variaciones hermenéuticas en las letras del siglo XII

El concepto de alegoría que se desarrolla en la Edad Media constituye un componente esencial de la literatura y, fundamentalmente, del pensamiento medieval. La Antigüedad suministró dos definiciones de ella: 1) metáfora prolongada y 2) tropo en el que a partir de una cosa se significa otra cosa de lo que se dice, definición dada por Heráclides Póntico (IV a.C.) y retomada por San Agustín, Isidoro de Sevilla y Beda el Venerable. Más que la primera, puramente gramatical, esta segunda era sensible a su valor hermenéutico y concordaba, por ende, con su utilización primera como método de exégesis. Buscar en las Sagradas Escrituras un sentido ulterior era un procedimiento al cual invitaban las parábolas de Cristo y la interpretación que él mismo daba del sembrador. Desde la época patrística, con Orígenes, San Jerónimo y San Agustín, la búsqueda del sentido segundo fue formalizado de manera que pudiera constituir el núcleo del razonamiento exegético. Se consideró, desde entonces, que cada pasaje de la Escritura poseía cuatro sentidos: literal, alegórico o espiritual, tropológico o moral y anagógico, relacionado con la escatología. En la Edad Media se emplearon preferentemente los tres primeros, ya que el anagógico tendió a confundirse con el alegórico. Los sermones y los comentarios universitarios de la Biblia invitaban a la elucidación sucesiva de estos tres. En consecuencia, desde el maestro en teología hasta el más simple de los fieles, quien semana tras semana escuchaba la homilía dominical, todos estaban acostumbrados a buscar detrás de la letra o de la apariencia un sentido segundo. No es, por tanto, legítimo sorprenderse ante el hecho de que la Edad Media haya interpretado las Escrituras, el mundo y la literatura según la alegoría ni de que haya elaborado una literatura profana destinada a ser leída de esta forma.

Sin embargo, el concepto cristiano de alegoría no es unívoco y, como explica Mawy Bouchard (2006), se presta a confusiones. Los autores medievales poseían una terminología precisa, aunque variada, de las distintas formas de distinguir la alegoría cristiana y los diversos sentidos figurados de los textos profanos. En esta línea de pensamiento, Édouard Jeauneau (1957), por ejemplo, indica que Guillermo de Conches utilizaba la palabra integumentum en sus diferentes glosas para designar el procedimiento que emplearon autores como Boecio, Platón y Virgilio para envolver sus pensamientos profundos bajo el vestido de la fábula.

Jeauneau (1957: 35) estipula también que era habitual que, cuando se pasaba de la exégesis bíblica a la de los escritores profanos, los maestros de gramática recurrieran a una clasificación de características similares a las usadas para la lectura de las Sagradas Escrituras. ${ }^{15}$ Desde esta perspectiva puede citarse el ejem-

15 Dante realiza una distinción similar en el Convivio, II, 1 cuando expresa: "Dico che, sì come nel primo capitolo è narrato, questa sposizione conviene essere litterale e allegorica. E a ciò dare a intendere, si vuol sapere che le scritture si possono intendere e deonsi esponere massimamente per quattro sensi. 3. L'uno si chiama litterale, [e questo è quello che non si stende più oltre che la lettera de le parole fittizie, sì come sono le favole de li poeti. L'altro si chiama allegorico] e questo è quello che si nasconde sotto 'I manto di queste favole, ed è una verita de ascosa sotto bella menzogna: come quando dice Ovidio che Orfeo facea con la cetera mansuete le fiere, e li arbori e le pietre a sé muovere; che vuol dire che lo savio uomo con lo strumento de la sua voce fa[r]ia mansuescere e umiliare li crudeli cuori, e fa[r]ia muovere a la sua volontade coloro che non hanno vita di scienza e d'arte: e coloro che non hanno vita ragionevole alcuna sono quasi come pietre. 4 . E perché questo nascondimento fosse 
plo de Arnulfo de Orleans que lo utilizó para explicar las Metamorfosis de Ovidio. Guillermo de Conches echó mano a igual práctica cuando comentó a Boecio, aunque, en lugar de emplear el término allegoria, usó el de integumentum. ${ }^{16} \mathrm{La}$ sinonimia de los dos términos se descubre asimismo si consideramos que las Allegoriae super Ovidii Metamorphosin de Arnulfo de Orleans son exactamente aquello que Juan de Garlandia llamó, en el siglo siguiente, los Integumenta Ovidii. A estos testimonios se suma el de Pedro Abelardo, quien utilizaba además y de forma indiferenciada los términos involucrum e integumentum. Respecto del primero, Abelardo afirmaba que esta forma era común tanto en los filósofos como en los profetas mientras que no dudaba en atribuir el segundo a las parábolas evangélicas. Sea cual sea el término empleado, se concluye que las mismas reglas de exégesis podían aplicarse tanto a los textos sagrados como a los profanos. Más aún, en función de estos ejemplos, Jeauneau puntualiza que "il est permis de conclure que l'integumentum est destiné à jouer dans la lecture des auteurs païens le rôle que joue l'allégorie dans la lecture de la Bible".

No obstante esta transitividad semántica de los vocablos, es necesario recordar que el integumentum puede adoptar diferentes formas, ya que su principal característica es la de acomodar su modo de significación a situaciones particulares. Representa también una manera concreta de apropiarse de la Verdad universal, ya que se configura como la traducción de una enseñanza bíblica a un lenguaje comprensible para grupos sociales de épocas y de regiones específicas. Si el comentario alegórico de las Sagradas Escrituras se limita a la glosa exegética, el integumentum, por su parte, implica no solo la glosa cristiana de las fábulas antiguas sino también una nueva composición de índole ficcional, cuyo objetivo es el de revelar (y ocultar) una verdad cristiana. Bouchard (2006:130) agrega, citando a Édouard Jeauneau, que la misma lección moral puede introducirse a través de varios integumenta y que un mismo integumentum puede tener múltiples significaciones. Pero más allá de ser una herramienta retórica importante para la escritura poética, el integumentumes particularmente útil para la formación filosófica puesto que permite desentrañar una enseñanza cristiana a partir de la lectura de los grandes textos paganos.

En este escenario, Bernardo Silvestre, uno de los principales representantes de la escuela de Chartres y autor, entre otros, de De mundi universitatae o Cosmographia y de un importante comentario a la obra virgiliana, ocupó un sitio de preeminencia. Étienne Wolff explica en Fulgence. Virgile dévoilé (2009) que, en el siglo XII, aún se consideraba a Virgilio la autoridad suprema en materia de sabiduría poética; de igual manera y en relación con el comentario de los auctores (actividad de iniciación intelectual y moral), Fulgencio fue un guía eficaz para develar el aspecto alegórico de la obra virgiliana. Este modo de explicar la Eneida fue ampliado y completado por Bernardo Silvestre, quien no solo suministró una etimología del

trovato per li savi, nel penúltimo trattato si mosterrà. Veramenti li teologi questo senso prendono altrimenti che li poeti; maperò che mia intenzione è qui lo modo de li poeti seguitare, prendo lo senso allegorico secondo che per li poeti è usato" [el resaltado es propio].

16 "Bella bis quinis. Quia dixerat sapientes cum omni fortuna bellum conserere, ad illud prelium hortatur nos in istis versibus tribus modis: per historiam, per integumentum, deinde ponendo premia que sequuntur" (citado por Jeauneau, 1957: 36) [el resaltado es propio]. 
nombre Eneas (ya implícita en Fulgencio) sino que también proporcionó la definición de integumentum: genus demonstrationis sub fabulosa narratione veritatis involvens intellectum unde et involucrum dicitur. ${ }^{17} \mathrm{La}$ idea de "velo de la ficción" permite establecer lazos entre poesía, mito, ciencia y filosofía. De amplísima difusión, el método alegórico enseñado en la escuela de Chartres ${ }^{18}$ era, desde el punto de vista del lector, una técnica de desciframiento, puesto que, para leer bien, debía asumirse el rol de intérprete; mientras que, desde el punto de vista del poeta, se trataba de una suerte de "confabulación", dado que un buen autor debía expresarse veladamente. En resumen, la teoría del integumentum fue empleada por mitógrafos y poetas pues aseguraba la dignidad de su actividad, distanciándola de la desprestigiada fábula y ganando, en definitiva, valor simbólico, ético y metafísico.

Estas digresiones históricas y los aportes de la crítica justificarían un estudio de El Caballero de la Carreta en clave alegórica. Pese a la constatación, dicha elección no me encolumna detrás de las propuestas de algunos medievalistas para quienes todos los romans de Chrétien reivindican, en grados diversos, una exegesis alegórica integral. En este sentido, es interesante retomar algunas de las objeciones de David Shirt (1978) cuando repasa las distintas líneas de análisis de El Caballero de la Carreta. Respecto del abordaje alegórico-simbólico, expresa:

The chief theoreticians for an allegorical-symbolical approach to the romances of Chrétien are Bezzola and D. W. Robertson [...]. "Taking the bit in his teeth and the Patrologia Latina off the shelf", to quote a recent critic, Robertson attempts to prove that courtly romance cannot and must not be read at face value, and that concealed in every work there lies a key to a hidden senefiance. For Robertson and his followers aesthetic beauty in literature is not an end in itself but is more of an instrument to eschatological and moral ends; medieval romance should therefore be properly interpreted using an exegetical method normally employed in medieval biblical criticism, the implication being that all medieval literature is basically didactic allegory in the service of Christian morality. According to this way of thinking, just beneath the surface of each octosyllabic couplet of Chrétien and every other romancier a patristic gremlim is lurking, always at hand to remind the listener/reader that romance is fundamentally for spiritual edification and not an excuse for imaginative flights of fancy (1978: 39).

Coincido con su idea de que un acercamiento únicamente alegórico a la obra del escritor champañés mediante la cual "probar que el amor cortés no puede ni debe ser leído al pie de la letra" o aquella que lee sus romans como "un instrumento para fines morales y escatológicos" estaría tergiversando uno los hallazgos estético-literarios más relevantes de la narrativa artúrica medieval frente a la producción francesa del periodo: el de liberar la literatura vernácula de los grilletes doctrinales propios de una textualidad edificante, por un lado, y el de juzgarla desde una perspectiva bíblica, por el otro. Sin embargo, resulta difícil descartar completamente la existencia de una interpretación alegórica, al menos de Lancelot o El Caballero de la Carreta, que restituya una concepción moral y cristiana de los episodios que lo integran.

17 "Integumentum es un género de demostración que envuelve bajo un relato fabuloso un sentido verdadero, es por ello que se la denomina también velo". 
Siguiendo una vertiente similar a la de David Shirt, los reparos de Philippe Walter (2003) al libro de Jacques Ribard Symbolisme et christianisme dans la littérature médiévale (2001) en especial a sus comentarios sobre El Caballero de la Carreta, resultan ser particularmente acertados, aunque tampoco coincido en un todo con Walter. En efecto, si bien Ribard cae en una suerte de compulsión alegórico-doctrinal, continúo pensando que la variante de esta figura, integumentum, no sería ajena a los intereses compositivos de Chrétien de Troyes. Las refutaciones de Philippe Walter llegan a su punto más álgido cuando se pregunta: "N'est-ce pas commettre un incroyable contresens que de voir dans le Chevalier de la Charrette, exaltation sulfureuse de l'adultère, une pieuse allégorie de la rédemption?". El interrogante, lejos de obturar la tesis alegórica, desnuda, por el contrario, el verdadero alcance de la mutación estilística con el que, desde mi perspectiva, Chrétien de Troyes innova y renueva su arte narrativo. En efecto, en El Caballero de la Carreta el integumentum induce a la cohabitación de dos sentidos, uno laico, prosaico y cortés y otro religioso y doctrinal, logrando rehuir la tensión ideológica que los llevaba a mutuamente excluirse. Este entendimiento es posible porque tanto la lectura literal como una exégesis simbólica transitan niveles de significación distintos, aunque paralelos. Así, las interpretaciones no se invalidan entre sí, sino que revelan una de las principales características de la figura y del método, como promotores de una vasta diversidad de elucidaciones posibles, cuyas verdades individuales se encuentra legitimadas por la auctoritas que las expone. La adopción del integumentum en El Caballero de la Carreta corroboraría la tesis de que el roman utilizó tempranamente recursos que expresaban la influencia de la cultura erudita sobre la profana y confirmaría la porosidad de los espacios de creación cultural medievales, reafirmando el impacto que produjo la estadía en la corte de Champagne en la escritura de Chrétien de Troyes. Este pasaje también pone al desnudo la relevancia conceptual y simbólica de ciertos elementos y técnicas propios del saber letrado, cuya adopción por parte de Chrétien de Troyes conduciría a formular, como adelanté, la existencia de dos periodos en su producción literaria.

\subsection{Figuras retóricas y etapas en la producción textual de Chrétien de Troyes}

Si observamos los romans del maestro champañés enfocándolos desde la vinculación que estos mantenían con la historia tristaniana, surgen divergencias entre ellos debido a la manera en que Chrétien parece haber encarado la rescritura de la leyenda, distinción que depende de la figura -ironía o integumentum- que el autor haya privilegiado en su composición. Desde esta perspectiva, podría arriesgar una división de toda su obra en dos bloques: uno conformado por Erec $y$ Enid, Cligès e Yvain y otro constituido por Lancelot o El Caballero de la Carreta ${ }^{19}$ y el Perceval o el Cuento del Grial. ${ }^{20}$ En el primer grupo, el escritor retomaría secuencias de los relatos tradicionales bretones, en general, y de la historia tristaniana,

19 Es importante recordar que la composición de Lancelot se produce de manera simultánea con la de $\mathrm{El}$ Caballero del León, como el narrador manifiesta en este último. Creo que el dato, más allá de proporcionar una información histórica valiosísima, puede también abonar la tesis del cambio de escritura que trato de probar.

20 La reunión de los romans en dos conjuntos no significa que todos compartan los mismos rasgos y elementos o que sus historias sean intercambiables; implica, únicamente y en función de la leyenda tristaniana, dos maneras de responder de manera semejante al embrujo de dicha historia. 
en particular, y los reformularía a fin de componer narraciones centradas en la dupla "armas y amor". ${ }^{21}$ Pero los relatos superan su función de entretenimiento y adquieren un matiz moral (o, quizás, entrelazan la delectación con la enseñanza) gracias a la utilización de la ironía que permite un distanciamiento censurador del narrador respecto de la materia narrada. En el segundo, por el contrario, cada roman ostenta una complejidad argumental que excede la temática binaria. En efecto, en el relato de las hazañas de Lancelot para liberar a su amada Ginebra, el caballero inicia su itinerario desde una presunta inferioridad que, no obstante, es rápidamente superada en el primer suceso posterior al episodio de la carreta, es decir, en la aventura del lecho encantado. De allí en más, Lancelot se obsesionará con la búsqueda de su dama, por lo que los combates con los adversarios que se cruzan en su camino ocuparán un lugar secundario en sus intereses. Cada nuevo enfrentamiento de armas no certifica únicamente que es el mejor guerrero del mundo, sino que es el más virtuoso y el más cortés de todos. De esta manera, Chrétien logra conjurar el hechizo tristaniano gracias al advenimiento de un héroe que, aunque parece imitar fielmente el comportamiento del otro, ${ }^{22}$ se distancia de él, debido a su conducta moralmente inmaculada, ${ }^{23}$ pese al adulterio que comete. Respecto de El Cuento del Grial, el vínculo con la leyenda sería inexistente y dicha ausencia, en mi opinión, se debe a que Lancelot inaugura una clase de héroe próximo al arquetipo del soldado de Dios (a quien solo supera su hijo Galaad) y que se plasma completamente en los ciclos en prosa del siglo XIII. ${ }^{24}$

21 Tanto Erec como Yvain caen en una crisis de identidad debido justamente al hecho de no haber sabido equilibrar, de forma inversa en cada caso, el amor a las armas con el que experimentaban hacia sus esposas; en ese sentido, podríamos decir que Chrétien problematiza dos rasgos centrales de la identidad guerrera de Tristán que no presentan conflicto alguno en las versiones de su historia.

22 "In Le chevalier de la charrette, for the first time, a pair of lovers take the stage who have subsequently become world-famous: Lancelot and Guinevere are no ordinary lovers and their liaison no run-of-the-mill affair. The genius of Chrétien is that he places his lovers in a paradoxical predicament, torn as they are between the conflicting claims of courtly and conventional morality, and in such a situation, adultery is an essential and integral part of their love; by allowing Lancelot and Guinevere to taste the fruits of their courtly passion, Chrétien underlines the basic frustrations and hopelessness of their mutual enthralment. When he forces the Charrette into an allegorical straitjacket, Ribard suppresses the very ingredient in the poem which gives it vitality -the tragedy of human dilemma" (Shirt, 1978: 43).

Los comentarios del medievalista respecto de la pareja Lancelot y Ginebra bien pueden describir la de Tristán e Iseo (por lo cual la afirmación "for the first time" resulta un tanto errónea). Esta circunstancia, a mi entender, confirmaría el estrecho vínculo entre los dos modelos. Sin embargo, insisto en mi lectura del roman de Chrétien según la cual Le chevalier de la charrette es una composición superadora de la leyenda tristaniana debido, justamente, a una posible exégesis del personaje de Lancelot y de su conducta en clave cristiana, la cual convive con una visión literal y cortesana. Respecto de la "tragedia del dilema humano" que encierran los amores de Lancelot y Ginebra, es necesario admitir que esta también se halla representada en la pasión de los amantes de Cornualles y que, en función de la existecia de una doble lectura, su valor no decrece, pese a la mirada simbólica que le pueda proveer dicha interpretación.

23 En la misma línea de pensamiento, Jørgen Bruhn incorpora la vision de Topsfield: "La Charrette is [...] one of Chrétien's mature romances (in contradistinction to Erec and Cligès): 'The ideal of reason and experience aa basis for temporal happiness is replaced by a quest, which leads through self-knowledge to humility, caritas, inner peace, and ultimately, in Perceval, to knowledge of God"' (2010: 79).

24 Si bien mi análisis intenta identificar en el Lancelot de Chrétien de Troyes algunos elementos característicos del ambiente místico que envolvía al Lancelot en prose, brindando una continuidad y una armonía de significados a los dos romans de Chrétien que los autores del siglo XIII prolongaron, desde otro ángulo, Jean Rychner ya había propuesto, con otros argumentos, la distancia que separaba a su caballero de los otros protagonistas de sus romans: "Sur ce point, le Conte du Graal, auquel on pensé invinciblement, est peut-être moins troublant. En effet, la petite communauté du graal, qui attend Perceval comme son libérateur, incarne les mêmes principes spirituels que Perceval doit ranimer en lui pour la sauver; or je ne sais pas retrouver dans la Charrette cette harmonieuse cohérence. Néanmoins, les héros de l'un et de l'autre roman partagent une clarté particulière, qu'ils me semblent devoir tous deux à cette folie, à cette exigence déraisonnable qui les éloigne de la commune morale arthurienne et chevaleresque, alors qu'Erec et Yvain -mais déjà moins Yvain qu'Erec- obéissent à la morale de leur milieu. Il y a déjà beaucoup de Perceval en Lancelot, ou encore beaucoup de Lancelot en Perceval: mêmes extases de part et de l'autre, même prédestination, même caractère messianique rédempteur, et même 
En síntesis, podría aventurarse, en última instancia, que, si Chrétien de Troyes buscó pergeñar un anti-Tristán en los primeros textos, durante la redacción de El Caballero de la Carreta descubre un no-Tristán, un modelo caballeresco que trasciende el heredado de las tradiciones vernáculas y en quien confluyen las cualidades de un aún germinal miles Christi.

Así, la rescritura en clave irónica de episodios característicos de las narraciones tristanianas en Erec $y$ Enid y en Cligès, principalmente, marcaría una primera etapa en la que el escritor compite con las versiones contemporáneas de la leyenda; luego, se establecería una segunda fase, desde El Caballero de la Carreta, en la que la historia se transforma en la littera de una significación otra o el integumentum, como diría Bernardo Silvestre, de una verdad oculta. Esta "alegorización" es particularmente visible en las escenas amorosas, en las que el prototipo caballeresco experimenta una transformación radical en la figura de Lancelot.

En la relación texto-contexto, por su parte, se confirmaría que la metamorfosis exhibe el contacto vivo entre dos mundos disímiles: el cortesano y el clerical, y entre una materia hasta ese momento desdeñada, la de Bretaña, y el pensamiento erudito. Si se acepta esta presuposición, podría aseverarse que el carácter alegórico del ciclo en prosa del siglo XIII (en especial, el de la La búsqueda del Santo Grial $^{25}$ constituye la lectura que los últimos romans de Chrétien inconclusos solicitaban, la cual los autores del Lancelot-Grial respetaron, devotamente, ${ }^{26} \mathrm{y}$ aprovecharon, con astuta perspicacia.

En función de estas especulaciones afirmaría, en última instancia, que en las cortes señoriales donde se diseminaron las historias de la llamada materia de Bretaña, la de Tristán e Iseo ocupó un lugar paradigmático, pues la relación de los amantes connotaba, de manera ejemplar, las exigencias de la moda sentimental que popularizaron los trovadores del mediodía francés y el valor guerrero preconizado por las narraciones bretonas. Chrétien, escritor al servicio de

violence 'sauvage' parfois, dans les gestes; ainsi lorsque Lancelot empoigne la cuisse du chevalier du gué, sel sache et tire et si l'estraint si duremant que cil se plaint (v. 817-818/807-808). Je devine pour ma part dans les exigences de l'amour à l'égard de Lancelot la préfiguration, le premier dessin de celles de la charité à l'égard de Perceval; les premières sont au fond, comme les secondes, de nature spirituelle; elles demandent aussi renoncement au monde et comme une conversion" (1968: 71) [el resaltado es propio]. Es justamente esta "prefiguración" de la caridad y la manera de narrativizarla las que separan a Lancelot de Tristán.

25 David Shirt apoya una tesis inversa: "The thirteenth-century 'architect' of the vast prose cycle of Arthurian romances, the Lancelot/Grail corpus, into which the Charrette story was incorporated, was either at a loss to find any allegory in Chrétien's original or was simply not interested in it although the presence in the prose cycle of La Queste du saint Graal, described by one critic as 'a forest of allegories', makes it difficult to believe that if Chrétien's romance was as allegorical as Ribard claims, the compiler of the Vulgate cycle failed to notice it."

El posicionamiento de Shirt adolece de la necesaria particularización que un análisis de estas características debería tener. Los romans de Chrétien de Troyes no pueden ser considerados como una unidad homogénea, sino que cada roman presenta particularidades que los individualizan. En este contexto, los relatos de Charrete y Graal se separan de los otros y se emparientan gracias a su carácter alegórico. Por otra parte, es preciso distinguir entre la allegoria bíblica y el concepto de integumentum que, si bien impone una lectura simbólico-moralizante, no implica una perspectiva ni bíblica ni escatológica. En segundo término, la incorporación de los sucesos más relevantes de estos dos romans de Chrétien a la suma artúrica Lancelot-Graal, en la que la lectura alegórica juega un rol determinante, no es casual ni aleatoria, sino que estaría demostrando que ese supuesto arquitecto encontró en las historias de Chrétien (y en sus continuadores, entre los que podemos incluir a Robert de Boron) una doble vía de significación, semejante a la que se desarrollaría en el gran ciclo.

26 A su vez, podría pensarse que escritores de los romans en verso habrían privilegiado, en contrapartida, una composición centrada en el ethos guerrero, en el código cortés y en la fantasía propia del folklore autóctono, es decir que habrían explotado las estrategias compositivas desplegadas en el primer grupo. 
diferentes mecenas, entre quienes se halla María de Champaña (hija de Leonor de Aquitania y Luis VII de Francia y descendiente, por vía materna, del trovador Guillermo IX de Aquitania), compuso relatos que empleaban algunos de sus elementos a fin de garantizarse una recepción favorable mediante obras que expresaban la influencia de las enarrationes poetarum ${ }^{27} \mathrm{y}$, muy especialmente, del roman antique (especialmente el Roman d'Eneas) que atestiguaban el prestigio de su formación. En este escenario, sus dos primeras obras (Erec $y$ Enid y Cligès) acusan la influencia mayor del folklore y de la ideología de la cortesía, a los cuales nutrió con interpretaciones personales, todo ello mediante un distanciamiento irónicamente crítico que le permitía transmitir una enseñanza de índole moral. Pero esta obediencia al gusto cortesano, no carente de una sutil rebeldía expresada retóricamente, parece desvanecerse durante la composición de El Caballero de la Carreta. En efecto, si bien continuó empleando fragmentos procedentes de la tradición, en este roman incorporó la novedosa posibilidad de interpretar alegóricamente al menos tres de sus pasajes centrales, referidos a la hazaña guerrera motivada por el amor. En consecuencia, logró que las secuencias dejaran de significar únicamente el mundo de la aventura guerrera y el de la fantasía compensatoria y que adicionaran un sentido segundo de orden espiritual. Desde esta perspectiva, en conclusión, no solo la alegoría le permitió suministrar a los episodios un significado diferente, sino que el amor profano pudo ser el velo que escondía el amor a la divinidad, como algunos críticos ya han estipulado.

Todo este andamiaje sustentará mi análisis de la humillación a la que se doblega voluntariamente el personaje de Lancelot en el episodio de la carreta.

\section{Interpretaciones plurales y guiños eruditos en El Caballero de la Carreta}

\subsection{Honor caballeresco y humildad cristiana: el descubrimiento de una coincidencia}

Consternado ante el secuestro de Ginebra y ansioso por alcanzar a su amada reina, Lancelot no duda, sino un infortunado instante, ${ }^{28}$ en subir a la carreta que un horrible enano conduce. Como cualquier receptor del texto colige luego de la minuciosa explicación que se brinda del uso dado a ese transporte, ser llevado en una carreta implica la absoluta humillación de Lancelot. El narrador indica que se trata de una especie de cadalso que trasladaba a ladrones, traidores y

27 Recordemos nuevamente el prólogo de Erec et Enide en el que opone la composición de su roman a la práctica de los cuentistas: D'Erec, le fil Lac, est li contes/ Que devant rois et devant contes/ Depecier et corrompre suelent/ Cil qui de conter vivre vuelent (vv. 19-22). (De Erec, el hijo del rey Lac, es el cuento/ Que ante reyes y ante condes/ Despedazar y corromper suelen/ Aquellos que de contar quieren vivir) [traducción propia].

28 La duda que le provoca esta acción le valdrá el reproche de Ginebra, como anticipa el narrador en esta sección del relato: Mar le fist et mar en othonte/ Que maintenant sus nesailli,/ Qu'ils'an tendrá por mal bailli (vv. 362-364). Traducción: [el caballero se ha detenido por momentos, sin montar]. ¡Por su desdicha lo hizo y por su desdicha le retuvo la vergüenza de saltar al instante a bordo! ¡Luego lo sentirá! (El caballero de la carreta: 24). Esta escena tendrá su contrapartida cuando Ginebra reprocha agriamente a Lancelot ese segundo de incertidumbre. 
delincuentes, exhibiéndolos públicamente. Es claro que, como el narrador también se encarga enfáticamente de señalar, la acción constituye una vergüenza y representa la pérdida del honor, eje y motor del ethos guerrero-caballeresco:

\author{
Mes Reisons, qui d'Amors se part, \\ Li dit que del monter se gart, \\ Si le chastie et si l'anseigne \\ Que rien ne face ne anpreigne \\ Dom il ait honte ne reproche (vv. 365-369). ${ }^{29}$
}

El debate entre las personificaciones de Razón y Amor exterioriza las tensiones internas que la propuesta del enano origina en Lancelot y pone de manifiesto la disyuntiva que, desde Erec $\gamma$ Enid, perturba a los protagonistas de los romans de Chrétien de Troyes. Más aún, cualquiera sea la decisión que Lancelot tome, esta supone desobedecer a uno de los dos mandamientos más importantes del código caballeresco. El juicio de Razón resalta la consecuencia, de orden moral, a la que conduce someterse a la proposición del carretero. Tan así es que Gauvain se niega rotundamente a aceptar el ofrecimiento del enano. ${ }^{30}$

En los versos citados descuella un vocablo en particular: honte (vergüenza). La palabra, como recuerda David Hult (1988), parece tener un origen franco ( ${ }^{*}$ haunipa) y mantiene una estrecha conexión con la ética característica de las sociedades guerreras. Conlleva la idea de daño físico, afrenta o deshonra. De acuerdo con Jones (citado por Hult), el término es recurrente en el Cantar de Roldán; significa lo opuesto a honor y con frecuencia se lo relaciona con la idea de revés. Fuera de la ética guerrera desplegada en los cantares de gesta, el vocablo admite otras significaciones que, en la misma línea, refieren las maneras en que la sociedad expresa su desagrado o condena ante un individuo que juzga indigno.

En la exhaustiva investigación que desarrolla, Hult releva 46 ocurrencias de honte en El Caballero de la Carreta y observa que muchos de los ejemplos conservan el significado tradicional épico, es decir, expresan la idea de una injuria o derrota en combate. Se trata, habitualmente, de un contexto público, pues resulta difícil aislar el fracaso del guerrero de su difusión y, consecuentemente, de su desprestigio ante la comunidad. En esta línea, el medievalista explora los sinónimos que se vinculan con honte y concluye que, a excepción de duel, angoisse e ire (duelo, angustia e ira), el resto denota agresión o reproche del exterior, es decir, reprobación pública. Por otra parte, señala que, si el término se origina en una sociedad feudal, cohesionada por una ética guerrera en la que el vigor y la conquista son cualidades altamente apreciadas, en El Caballero de la Carreta se observa un incipiente movimiento hacia la internalización del sentimiento como reconocimiento personal de una desgracia. Sin embargo, para Hult no se trata aún de una emoción originada completamente en el interior del individuo

29 "Pero Razón, que de Amor disiente, le dice que se guarde de montar, le aconseja y advierte no hacer algo de lo que obtenga vergüenza o reproche" (El caballero de la carreta: 24).

$30 \mathrm{El}$ hecho se justifica también porque el sobrino del rey Arturo no ha perdido su caballo, como le sucede a Lancelot. 
pues: "[...] as an objectivized social attribution, it is passed from person to person, a person litterally 'has shame' when society has given it to him" (1988:33). Aunque admite esta inicial incorporación de la vergüenza, sostiene que el reconocimiento de una calamidad pública o social no equivale al sentimiento espontáneo de culpa y timidez que la caracteriza en nuestros días. En este sentido, todos los ejemplos y la argumentación que Hult presenta están orientados a probar que el peso de la opinión pública ${ }^{31}$ y de la valoración negativa que recae sobre quien ha sido víctima de un infortunio priman también en el roman de Chrétien de Troyes. De esta manera, se descartaría la idea contraria ${ }^{32}$ que lee, en la conducta de Lancelot, una conciencia y una internalización de la culpa, en particular luego de la hiriente y fría bienvenida que recibe de Ginebra.

Las ideas de David Hult explican, en mi opinión, los comportamientos de Lancelot y de Gauvain frente a la carreta, mientras que la recepción que los pobladores del castillo al que son conducidos por el enano refrendan el vínculo entre el sentimiento de vergüenza y la evaluación pública de un acto deshonroso. En esta aventura, la conducta de Lancelot realza su figura de amante ejemplar dado que, como integrante de la orden de caballería, comparte el significado moral que la comunidad atribuye a estos actos y discierne claramente la humillación a la que se expone; sin embargo, como excelso fins amanz entiende que ningún rebajamiento es suficiente si con ello logra salvar a su reina. Y opta. Lancelot escoge a su dama antes que sus responsabilidades caballerescas. Pero titubea un instante. Y esa dubitación, según el parecer del narrador, "Mar le fist et mar en ot honte"33 supondrá el desprecio de Ginebra. La respuesta de la reina revela que ella también entiende el acto de ser transportado en carreta como una deshonra pública y que, por ello, Lancelot debería haber aceptado, sin vacilar, mancillar su honor por el amor a su dama. La cólera de Ginebra se enciende porque el Lancelot amante parece haber flaqueado y no antepuso su pasión a su honor.

Respecto de la actuación del héroe, podría asimismo inferirse la existencia de otro código moral en el que la humillación no es motivo de rebajamiento sino, por el contrario, de honra y glorificación. En esta línea de pensamiento, sería fructuoso retomar los comentarios que Michel Zink expuso en el curso "Humbles et humiliés. Récits médiévaux de l'abaissement" dictado en 2011, en el marco del seminario anual que ofrece desde su cátedra "Literaturas de la Francia medieval” del Colegio de Francia. ${ }^{34}$ Como el especialista refiere, el mundo medieval

31 "One of the important factors revealed by this and the following example is that, while we cannot say that honte does not exist as an internalized feeling or emotion, it simply does not occur apart from a social event or occurrence motivating the feeling within a public context" (Hult, 1988: 36).

32 Hult admite la internalización del sentimiento de vergüenza en el primer tercio del siglo XIII, en obras como el Lancelot en prose o el Roman de la Rose. Y agrega: "but this internalization of honte accounts for only a limited percentage of the term's occurrences in the Charrette's and even the it is always used to express a character's reaction to a situation which has in public or social terms produced (or is likely to produce) disapproval on the part of others".

33 Este verso es también examinado por David Hult, quien explica que proviene de la copia Guiot; a partir de este verso podría suponerse que Lancelot siente, en su interior, la vergüenza de su acto. Sin embargo, proporciona la versión del manuscrito T en el que se lee "mar le fist, mar i douta honte", en el que douter significa "temer". Concluye que Lancelot "temió" la vergüenza [pública]. 
descansa sobre una sociedad del honor que, paradójicamente, adopta una religión que no solo preconiza la humildad, sino que se funda en una escena humillante, la de la pasión de Cristo. Esta civilización se debatió entre una religión que encumbraba la degradación y una sociedad que la temía y abominaba; profesaba un culto que incitaba a la humildad y a la pobreza mientras que sus integrantes se inclinaban por el brillo, el poder y el dispendio; adhería a una creencia que oponía a la ostentación de los falsos valores mundanos los verdaderos, los cuales se desplegaban en la intimidad y en el secreto. En resumen, el hombre medieval estaba tironeado entre una religión que invitaba al desposeimiento de sí y una sociedad que inducía a la afirmación del yo.

Zink nos recuerda también que la Edad Media consideraba la humillación en relación con la humildad y refiere el hecho de que uno y otro término comparten su etimología (humus). No obstante, poseen matices que los distinguen entre sí y que se expresan claramente en la imprecación de San Bernardo: ¡cuán humillados son quienes no son humildes! En la humillación se destaca, por otra parte, el hecho de que sea un sufrimiento que se siente o se inflige en el universo de los signos; se trata tanto de un padecimiento simbólico como de una realidad; más aún, es precisamente el signo el que transforma la realidad en dolorosa. En las culturas occidentales, la humillación solo puede ser sancionada por el cuerpo social y en referencia a sus valores; más aún, la comunidad necesita que la vergüenza sea algo aterrador, ya que el respecto a las normas depende de ello. Las sociedades medievales no son una excepción a esta regla y esto no llamaría la atención si no fuera por la contradicción que supone la introducción del cristianismo. En este contexto social, se entiende la relevancia que poseen los espectáculos de ejecuciones y suplicios: la vergüenza de la flagelación pública resulta ser efectiva más por ser humillante que por ser un sufrimiento físico. Pese a todo ello, estamos ante una civilización modelada por una religión que predica la humildad y que se funda sobre una figura de humillación, "une religión qui se plaît à inverser les valeurs de la gloire et de la honte" (Zink, 2011: 575). ${ }^{35}$

El medievalista explica, por otra parte, que el texto más relevante sobre la humildad de Cristo, el que inspira a san Agustín y por su intermedio a toda la tradición cristiana, aquel que reúne, por un lado, la humildad de Cristo y la de los hombres llamados a imitarlo y, por otro lado, la humildad de Cristo y la humillación de la cruz es la Epístola a los Filipenses (2, 3-11) de San Pablo. En ella se expone una teoría del rebajamiento de Cristo y se justifica el hecho de que se pueda obtener la gloria en la cruz (Gal, 6, 14), suplicio extremo de esclavos y malhechores "escandalo para los judíos y locura para los griegos", como expresa en un pasaje célebre de la Primera Epístola a los Corintios (Cor, 1, 18-25). La degradación que

35 Y agrega: "Ni par son héritage antique ni par ses structures sociales largement empruntées au monde germanique, le monde médiéval n'était préparé à faire de l'humilité une valeur. L'humilité est proprement une vertu chrétienne. Ou plutôt, avant d'être une vertu chrétienne, c'est une vertu biblique. L'homme, façonné de la terre (humus) ne peut être que humilis devant Dieu. Dans les livres de l'Ancien Testament, c'est seulement dans la relation à Dieu que l'humilité de l'homme est une vertu. Plus tard seulement elle en devient une dans sa relation avec les autres hommes (Ben Sirac 3, 18-20). Elle prend tout son importance dans le Nouveau Testament: face à la venue du Royaume de Dieu et à l'infusion de la grâce, l'homme ne peut compter sur ses mérites pour être justifié (le pharisien et le publicain, Lc 14, 11). Les deux aspects se combinent dans le Magnificat $(L c 1,46-55)$ qui est pour une bonne part un centon vétérotestamentaire" (575). 
Cristo acepta por los hombres debe ser ejemplo de aquel que cada uno debe imponerse frente a los otros. Este tipo de vergüenza debe llegar hasta el extremo de la humillación de la cruz, aunque se trate de una ignominia, la cual, sin embargo, se transforma en gloria gracias a la resurrección.

Aunque el pensamiento medieval, continúa Zink, prefirió la dialéctica paulina de la humildad, la humillación y la gloria antes que el amargo y único espectáculo de la humillación, existían ejemplos de su sola presencia en las escenas de rebajamiento que se manifestaban en la liturgia de la Semana Santa o en los numerosos tratados de devoción como ejercicio espiritual.

En este horizonte, las reflexiones de Bernardo de Claraval ocupan un sitio de privilegio. En efecto, el teólogo considera que la humildad posee un valor absoluto y se define en grado superlativo, no comparativo. Gracias a la verissima sui cognitione (el verdadero conocimiento de si mismo), el hombre toma conciencia de su miseria y comprende que la humildad es, ante todo, una actitud frente a Dios. Representa, por un lado, el sendero de la caridad, pues conocer la propia miseria induce a la compasión del prójimo y, por el otro, el camino de la contemplación, por cuanto la purificación que nace del conocimiento de sí mismo elimina la escoria de las vanas ilusiones. La humildad es, en definitiva, olvido de sí mismo. En su Tratado sobre los grados de humildad y soberbia, Bernardo de Claraval enfatiza el valor de la interiorización de la vergüenza pública, como sentimiento de culpabilidad, y su posterior metamorfosis en arrepentimiento, gracias a la conversión del corazón. Zink ve en este proceso el movimiento que va de la humillación a la humildad.

Ahora bien, no es este tratado de San Bernardo acerca de la humildad y su relación con la humillación sino sus sermones 34 a 42 sobre el Cantar de los Cantares los que, en especial, desarrollan su opinión del tema. En el sermón 34, "Los que aspiran a cosas sublimes deben abrazar el camino de la humildad", Bernardo expresa:

[...] cuando veas que te humillan acéptalo como una señal propicia y una prueba cierta de que la gracia de Dios está cerca. Porque, así como delante de la ruina va la soberbia, delante de la exaltación va la humillación. Has leído ambas cosas: Dios se enfrenta con los arrogantes, pero concede su gracia a los humildes. Cuando juzgó oportuno premiar con una amplia bendición a su siervo Job, después de la magnífica victoria de su inmensa y probada paciencia, ¿no hizo cuanto pudo para humillarlo previamente con muchas pruebas severas, preparando el camino de la bendición?

Mira lo que dice: con muchísimo gusto presumiré de mis debilidades, porque así residirá en mí la fuerza de Cristo. No dice que soporta con paciencia sus debilidades: presume de ellas y con mucho gusto. Así demuestra que la humillación es su gran delicia, y que no sirve para nada ser dueño de sí mismo por la paciencia, mientras no reciba la gracia, porque se ha humillado espontáneamente. Escucha este principio general: al que se abaja lo ensalzarán. Lo cual significa que no toda humildad se ve encumbrada; debe nacer de la voluntad, no de la tristeza ni de la necesidad. Por el contrario, no serán humillados todos los ensalzados, sino el que se ensalza a sí mismo, es decir, 
por su propia vanidad. Y al revés: no es encumbrado el humillado, sino el que se humilla espontáneamente, es decir, por el mérito de su voluntad. Suponed que la ocasión de la humildad es algo externo, por ejemplo: oprobios, quiebras de fortuna, suplicios. Sólo si se acoge todo esto con una conciencia resignada y alegre, y por amor de Dios, se podrá decir que no ha sido humillado por otros, sino por sí mismo (304).

\subsection{Humillación, honor y las posibilidades de las exégesis}

Los dos estudios que he seleccionado para examinar el episodio de la carreta exponen de manera clara el sesgo que pretendo dar a mi análisis. El estudio de David Hult sobre el carácter social del honor medieval, por un lado, y las consideraciones de Michel Zink respecto de la vergüenza, la humillación y la humildad, por el otro, describen dos de las interpretaciones que puede contener el episodio de la carreta. La adopción de una u otra dependía mayormente de la formación intelectual del auditorio que escuchaba la lectura del roman. Para la sociedad cortesana de María de Champaña, la deshonra pública de Lancelot era el precio a pagar por su amor a Ginebra. Para los letrados que frecuentaban dicho espacio, el cuento vano de Bretaña podía esconder un significado próximo a la mística especulativa de Bernardo de Claraval. ${ }^{36}$

Se trata de una adición de sentidos que reclama una lectura doble del episodio: tanto en clave caballeresca como cristiana. En otras palabras, el pasaje autorizaría una lectura alegórica. En esa doble disposición, Chrétien de Troyes no habría traicionado ni al auditorio cortesano, que buscaba desentenderse de las exigencias doctrinales de la literatura de diversión, ni al público clerical, para el cual la letra debía ser sustento de enseñanza.

Gracias al episodio de la carreta, el autor responde también a los mandamientos de la fin'amor representados, desde el prólogo, por las demandas de su mecenas, María de Champagne. Por otra parte, en su papel de narrador, consigue hilvanar una progresión ascendente que encadena diferentes aventuras, recurso

36 La afirmación puede resultar desmedida, pues implicaría que Chrétien de Troyes estaba familiarizado con el pensamiento de Bernardo de Claraval. No obstante, ese conocimiento pudo darse por la intermediación de Nicolas de Montiéramey, cuya biografía resume Anne-Marie Turcan-Verkerk: "Dans l'entourage d'Henri le Libéral, Nicolas de Montiéramey était devenu à partir de 1158 le 'spécialiste' de l'écriture épistolaire, que le comte de Champagne appelait 'son très cher maître' (donations pro amore karissimi mei magistri Nicolai). D'abord chapelain de l'évêque de Troyes Hatton (il apparaît comme tel dès 1138, à travers la correspondance entre Hatton et Pierre le Vénérable), ce Bénédictin de Montiéramey rejoignit son abbaye puis Clairvaux après l'entrée d'Hatton à Cluny, à la fin de 1145 ou au début de 1146, et devint rapidement l'un des secrétaires de Bernard de Clairvaux. Ami de Pierre le Vénérable, il avait déjà servi les intérêts de Bernard en portant au pape, en 1140-1141, des lettres concernant Abélard - à la rédaction desquelles il avait peut-être déjà participé, comme le suggère le manuscrit Phillipps 1732. Trois billets de recommandation envoyés par Bernard à Innocent II entre 1138 et 1143 semblent le concerner (Epist. 434, 435, 436 Leclercq-Rochais), et montrent que s'il servait Hatton, il le faisait en obéissant à Bernard [...]. En 1152, Bernard de Clairvaux jeta l'opprobre sur Nicolas en l'accusant entre autres d'avoir volé son sceau, de l'argent et des livres, que l'on retrouva effectivement sur lui (Bernard, Epist. 298 Leclercq-Rochais), mais peut-être sans qu'il y ait eu malhonnêteté de sa part ; Bernard craignait surtout que son secrétaire n'eût envoyé au pape des lettres de lui à son insu. Bien que les lettres de Pierre le Vénérable ne concernent plus Nicolas après $1152, \mathrm{G}$. Constable pense que cette affaire n'a sans doute pas signé la fin de leur amitié ; elle n'empêcha pas en tout cas le pape Adrien IV d'accorder son soutien à Nicolas après la mort de Bernard. Après quelques années d'absence - de France peut-être, des sources sûrement entre 1152 et 1156 - et un séjour à Rome auprès de la curie, Nicolas retrouva son ancienne abbaye de Montiéramey (vers 1158). C'est à cette époque qu'il devint une espèce de conseiller littéraire voire plus précisément le chancelier 'privé' d'Henri le Libéral, qui, nous l'avons vu, lui vouait une affection et une admiration particulières, et le fit prieur de Saint-Jean-en-Châtel à Troyes dès 1160 . Notons au passage que le document le plus récent transmis avec l'Aurea gemma gallica est daté de la cour de Champagne, en 1159. Nicolas fut également chanoine de la collégiale SaintÉtienne de Troyes, fondée par Henri dans son palais comtal. Il mourut en 1178 ou peu avant" $(2015: 70,72-73)$. 
característico de su poética, en el que el protagonista tropieza en su ruta con una falla o defecto que lo disminuye en su valía moral y lo sume en una crisis de la cual resurge paulatinamente, hasta alcanzar una posición de excelencia superlativa.

\section{A guisa de conclusión (preliminar)}

Podríamos aventurar que esta "obsesión" con la leyenda tristaniana por parte de Chrétien de Troyes puede ser indicio de que, en las cortes ligadas, de alguna forma, a la dinastía angevina, la historia de los amantes de Cornualles era un relato exitoso desde el punto de vista de la recepción, una suerte de "best-seller"; como todo hecho literario de cierta popularidad, Chrétien de Troyes bien pudo concebir un modelo que intentara desestabilizar esa hegemonía.

Desde esta perspectiva y a la luz de aquello que, considero, alcanza con el modelo de Lancelot, los romans de Erec, Cligès e Yvain serían experimentos con los que trató de rivalizar creando un mito nuevo que desplazara de esa posición jerárquica a Tristán. En ese sentido, podríamos interpretar a la carreta como el componente opuesto al brebaje y ambos como sinécdoque del nacimiento de mitos de amor. A diferencia de Tristán (y de sus propios modelos "fallidos", Erec, Cligès e Yvain), en El Caballero de la Carreta logra integrar las armas con el amor sin prescindir del elemento central, del componente básico del mito tristaniano, el "adulterio", que, en los otros casos, había rehuido. Con Lancelot, Chrétien estaría clausurando una narrativa centrada en proponer un modelo alternativo a la narración más seductora y exitosa de los cuentistas bretones.

Finalmente, este modelo nuevo caracterizó un personaje que permitiría la doble lectura: literal y alegórica. En efecto, Lancelot-amante expresaría también no solo eros sino también ágape, una comunión del hombre con Dios. De esta manera, los estrictos principios de la fin'amor trascienden el mundo terrenal y mutan hacia una vinculación con la divinidad. 


\section{Bibliografía}

" Bogdanow, F. (1972). The Love Theme in Chrétien de Troyes's Chevalier de la Charrette. En The Modern Language Review, vol. 67, núm. 1, pp. 50-61.

"Bouchard, M. (2006). Critique de la fable historiographique. Rabelais et les 'niveaux de destination'. En Avant le roman: l'allégorie et l'émergence de la narration française au 16ème siècle, pp. 129-133. Ámsterdam: Rodopi.

" Bruhn, J. (2010). Lovely violence. Chrétien de Troyes' Critical Romances. Cambridge: Cambridge University Press.

"Chrétien de Troyes (1990). Le Conte du Graal. Edición crítica, traducción y notas de Charles Méla. París: Le livre de poche. Colección Lettres Gothiques.

" Chrétien de Troyes (1992a). Erec et Enide. Edición crítica, traducción y notas de JeanMarie Fritz. París: Le livre de poche. Colección Lettres Gothiques.

"Chrétien de Troyes (1992b). Le Chevalier de la Charrette. Edición crítica, traducción y notas de Charles Méla. París: Le livre de poche. Colección Lettres Gothiques.

"Chrétien de Troyes (1994a). Yvain ou le Chevalier au Lion. Edición crítica, traducción y notas de David Hult. París: Le livre de poche. Colección Lettres Gothiques.

" Chrétien de Troyes (1994b). Cligès. Edición crítica, traducción y notas de Marie-Claire Gérard-Zai. París: Le livre de poche. Colección Lettres Gothiques.

"Delage, M. J. (1979). Quelques notes sur Chrétien de Troyes et le Roman de Tristan. En Mélanges de langue et littérature françaises du Moyen Age offerts à Pierre Jonin. Aix-enProvence: Presses Universitaires de Provence, pp. 211-219.

" Haidu, P. (1982). Le sens historique du phénomène stylistique: la sémiose dissociative chez Chrétien de Troyes. En Europe. Revue littéraire mensuelle, vol. 60, núm. 642, pp. 36-47.

" Hult, D. (1988). Lancelot's shame. En Romance Philology, vol. XLII, núm. 1, pp. 30-50.

" Jeauneau, E. (1957). L'usage de la notion d'integumentum à travers les gloses de Guillaume de Conches. En Archives d'Histoire Doctrinale et Littéraire du Moyen Âge, núm. 24, pp. 35-87.

"Kelly, D. (1992). Roman: Ordre and Parties. En The art of medieval French romance. Wisconsin: The University of Wisconsin Press, pp. 263-306.

" Marie de France. (1994). Lais. Introducción, traducción y notas de C. Alvar. Madrid: Alianza Editorial.

" Moran, P. (2014). La poétique et les études médiévales: accords et désaccords. En Perspectives Médiévales, 35, http://peme.revues.org/4439 (Consulta: 27-3-2017).

" Raabe, P. (1987). Chrétien's Lancelot and the Sublimity of Adultery. En University of Toronto Quaterly, vol. 57, núm. 2, pp. 259-269.

" Ribard, J. (1972). Chrétien de Troyes. Le chevalier de la charrette: essai d'interprétation symbolique. París: Nizet.

" Rychner, J. (1968). Le sujet et la signification du Chevalier de la Charrette. En Vox Romanica, vol. 27, núm. 1, pp. 50-76.

"Shirt, David J. (1978). Chrétien's Charrette and Its Critics, 1964-74. En The Modern Language Review, vol. 73, núm. 1, pp. 38-50. 
"Stirnemann, P. y D. Poirel. (2006). Nicolas de Montiéramey, Jean de Salisbury et deux florilèges d'auteurs antiques. En Revue d'histoire des textes, vol. I, pp. 173-188.

" Tomaryn Bruckner, M. (2000). The shape of medieval French romance. En R. Krueger (ed.), Cambridge Companion to Medieval French Romance, pp. 13-28. Cambridge: Cambridge University Press.

"Turcan-Verkerk, A-M. (2015). L'introduction de l'ars dictaminis en France. Nicolas de Montiéramey, un professionnel du dictamen entre 1140 et 1158. En Grévin, B. y Turcan-Verkerk, A-M. (eds.), Le dictamen dans tous ses états. Perspectives de recherche sur la théorie et la pratique de l'ars dictaminis (Xle-XVesiècles), pp. 63-98. Turnhout: Brepols.

"Walter, Ph. (2003). Jacques Ribard, Symbolisme et christianisme dans la littérature médiévale (Honoré Champion, 2001). En Cahiers de Civilisation Médiévale, vol. 46, pp. 290-292.

"Walter, Ph. (1993). Naissances de la littérature française (IXe - XVe siècle). Anthologie commentée. Grenoble: ELLUG.

"Wolff, E., Graziani, F. (2009). Fulgence. Virgile dévoilé. Villeneuve d'Ascq: Presses Universitaires du Septentrion.

"Zink, M. (1981). Une mutation de la conscience littéraire: le langage romanesque à travers des exemples français du XIle siècle. En Cahiers de Civilisation Médiévale, vol. 93, pp. 3-27.

" Zink, M. (1987). Chrétien et ses contemporains. En Lacy, N., Kelly, D., Busby, K. (eds.), The Legacy of Chrétien de Troyes, pp 5- 32. Tomo I. Amsterdam: Rodopi.

"Zink, M. (2011). Curso de la Cátedra de Littératures de la France Médievale, Collège de France Humbles et humiliés. Récits médiévaux de l'abaisement. 